\title{
Proximal Processes While Problem Solving in Formal and Game Environments
}

\author{
Lorraine A. Jacques \\ Louisiana Tech University, College of Education, Ruston, UNITED STATES
}

Received: 26 December 2019 • Accepted: 9 March 2020 - Published Online: 2 April 2020

\begin{abstract}
Problem solving follows a cycle of inquiry where the individual iterates between finding possible paths and exploring their likely effectiveness before selecting one as a possible solution. The cycle is enhanced through proximal processes because the number of paths that can be explored in depth are greater when more people work on the same problem. This paper discusses the cognitive aspects of problem solving, how proximal processes, specifically collaborations, affect problem solving, and how proximal processes work in formal and game problem solving environments. The primary finding is that proximal processes benefit problem solving mostly by providing explanations, but only when the collaboration is structured so that a lesser-skilled participant in the collaboration is explaining to a higher-skilled participant. This finding is common to both formal and game environments.
\end{abstract}

Keywords: proximal processes, problem solving, collaboration.

\section{Introduction}

Current curricular frameworks are emphasizing the need for students to learn how to communicate and work collaboratively because the problems that they will face as adults are too complex for one person alone to solve. The Partnership for $21^{\text {st }}$ Century Learning (2015) places communication and collaboration equal to critical thinking skills as necessary for learning and innovation. Both the ELA Anchor Standards and the Mathematics Practice Standards in the Common Core State Standards list speaking to, listening to, and reasoning with others as essential skills for critical thinking in language arts and mathematics (National Governors Association Center for Best Practices, \& Council of Chief State School Officers, 2010). These and other frameworks suggest that proximal processes are essential for successful problem solving, but (1) what are the characteristics of these proximal processes, and (2) how do they affect problem solving?

An additional aspect to consider is problem solving as it relates to context. James Gee argues that serious games are natural environments for both problem solving scenarios and proximal processes, but school is not. In serious games, players interact with other players and/or non-player characters in order to gain skills, resources, and possible solutions for the problems presented in the game. Additionally, players form affinity spaces, which are networks of other people with like interests for the purposes of sharing information, mentoring, and extending the game world beyond its original design (Gee, 2007). School, however, still relies on individual effort and assessment. The primary flow of information is linear rather than networked; policies inform

(C) Authors. Terms and conditions of Creative Commons Attribution 4.0 International (CC BY 4.0) apply. Correspondence: Lorraine A. Jacques, Louisiana Tech University, College of Education, Ruston, LA, UNITED STATES. E-mail: ljacques@latech.edu. 
teachers what knowledge is valued, which teachers then pass to students (Gee, 2013). Yet as the curricular frameworks suggest, peer-collaboration may be increasing in schools as teachers and policies seek to implement these standards effectively. Workplaces have followed a similar transition over the past twenty years (Partnership for $21^{\text {st }}$ Century Learning, 2015). These changes suggest a third question: (3) How do proximal processes work in formal versus gaming environments?

- Collaborative problem solving uses the same process as individual problem solving.

- Individual skills increase when participants provide explanations to each other.

- Group skills increase when participants are willing to take risks.

- The group's social skills have greater impact than individuals' social skills.

- Games are natural environments for developing group and individual skills.

This paper will explore the research on collaboration and problem solving as a start towards answering these questions. First, individual approaches towards problem solving will be described as a foundation for the rest of the discussions. This foundation will then be applied to the research on how collaboration impacts problem solving. To compare proximal processes in formal and gaming environments, this paper will then review the research on collaboration in these spaces. Articles were found using Academic Search Complete, Education Full Text, ERIC, and Google Scholar and included proximal processes, problem solving, cognition, games/gamers, collaboration, and epistemology as search terms. Although the searches resulted in hundreds of articles, only ten addressed collaboration and its impact on problem solving, and only thirteen addressed how problem solving and collaboration combined in school, work, or games. The remaining articles addressed tools that could measure problem solving or collaboration, interventions to increase one or the other, effects on creativity or motivation, deficits with specific populations such as criminals, or the need to combine problem solving with inter-agency collaboration for specific scenarios and so were not included in this review.

\section{Cognitive aspects of problem solving}

A person has a problem if the person wants a solution but does not have one (Goldman, 1983). These problems may be convergent (goal is known) or divergent (goal is not known or unclear) and may have one or multiple paths towards a solution (Zhong, Wang \& Chiew, 2010). The act of problem solving is both overt and internal; an individual will gather information (overt) and apply it to an inquiry process (internal) (Goldman, 1983). Zhong et al. (2010) describe these as external and internal worlds that work together to form mental models of the problem. The real entities of the external world are visualized internally as virtual entities, which are then represented as abstract objects so relationships between them may be explored internally. When the relationships are weak, which happens when the person lacks experience with a similar problem or scenario, other abstract objects are derived in order to determine if those have relationships which might apply to the current real problem.

The inquiry process consists of generating a hypothesis, pursuit of possible solution paths, mentally testing one of the possibilities, and making a decision (Goldman, 1983). Cognitively, the person identifies objects and attributes, explores possible approaches by considering alternate goals and paths, evaluates one of these approaches, and either repeats the process or represents the chosen approach in order to apply it to the current problem (Zhang et al., 2010, see Figure 1). Therefore, problem solving is a process of search and represent (Zhang et al., 2010). This process, however, is greatly influenced by how the information is presented to the person because cognitively the person begins selecting possible solution paths based on the first information presented (Goldman, 1983), which affects what the person considers appropriate for changing the situation and determining success (Zhang et al., 2010). This influence of presentation 
and representation happens because people generally want only one solution to a problem even when multiple solutions exist (Goldman, 1983).

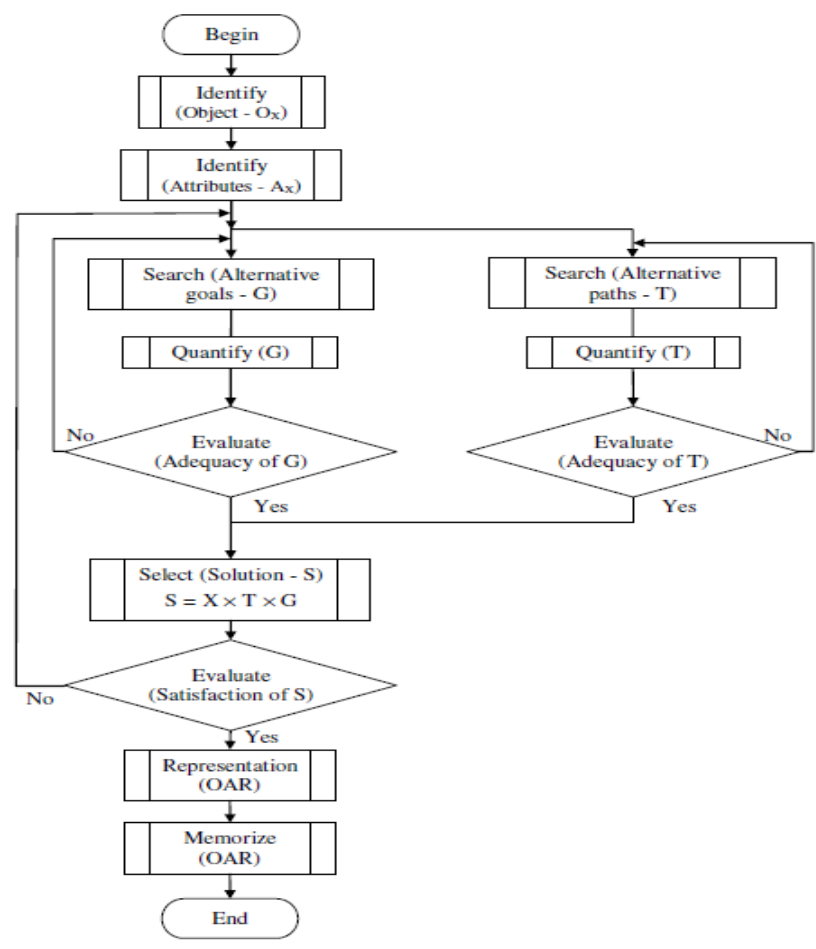

Figure 1. A cognitive model of the inquiry process (Zhang et al., 2010)

Another factor that influences the inquiry process is the level of experience the person has with the scenario. Bilalic, McLead and Gobet (2009) studied expert chess players in order to understand how experience with a particular board state affected the way they strategized in the game. Strategizing in chess generally consists of studying the current board state and hypothesizing the opponent's reaction to the various actions open to the player. Each actionreaction visualization is known as seeing a move ahead. In previous work, they learned that there are two approaches a player can use when strategizing: One can explore several possibilities for only a couple of moves ahead or one can explore one possibility for several moves ahead. Each carries risk; a shallow search may not reveal a difficulty further along the path but an in-depth search wastes time and resources if it is the wrong path. The expert player minimizes risk by applying the current board state to past experience, thus reducing the number of paths she will consider and allowing each to be explored in more depth.

For this study, Bilalic, McLead and Gobet (2009) determined the category of the specialization of each player (French defense or Sicilian defense) then presented each with four different board states: one in their area of specialization, one in the other area of specialization, one that favored neither category, and one that was a random placement of pieces on the board. They found that players had the easiest time recalling board positions for their area of specialization and the most difficult time recalling the random placement. Similarly, each player chose an in-depth search when in their area of specialty and a several-but-shallow search for all other board states. This suggests that the more experience one has with a problem, the easier it is to eliminate incorrect solution paths, allowing more cognitive resources to be used for internal representation. If one lacks sufficient experience, however, would proximal processes be an effective substitution? 


\section{Collaboration and problem solving}

Warner, Letsky and Cowen (2005) proposed a model of the group and individual cognitive processes at various stages of collaboration. As Figure 2 shows, these stages are knowledge construction, collaborative team problem solving, team consensus, and evaluation/revision. The knowledge construction stage is similar to the overt/internal problem solving activity that Goldman (1983) describes for individuals; even though people are working together, at this stage individuals are gathering data and building mental models to represent the problem. During the problem solving stage, these individual knowledge bases are integrated to form group-wide understanding and to begin the exploration of possible solutions. This alters the individual mental models to match the shared understanding of the problem and allows each member to explore a smaller number of possible solution paths in greater depth while collectively ensuring that a larger breadth of possible paths are explored. During the team consensus stage, individuals negotiate the possibilities they explored to collectively agree on a solution. Finally, during evaluation and revision the solution is collectively analyzed to determine if it matches the team's goals or if adjustments are needed.

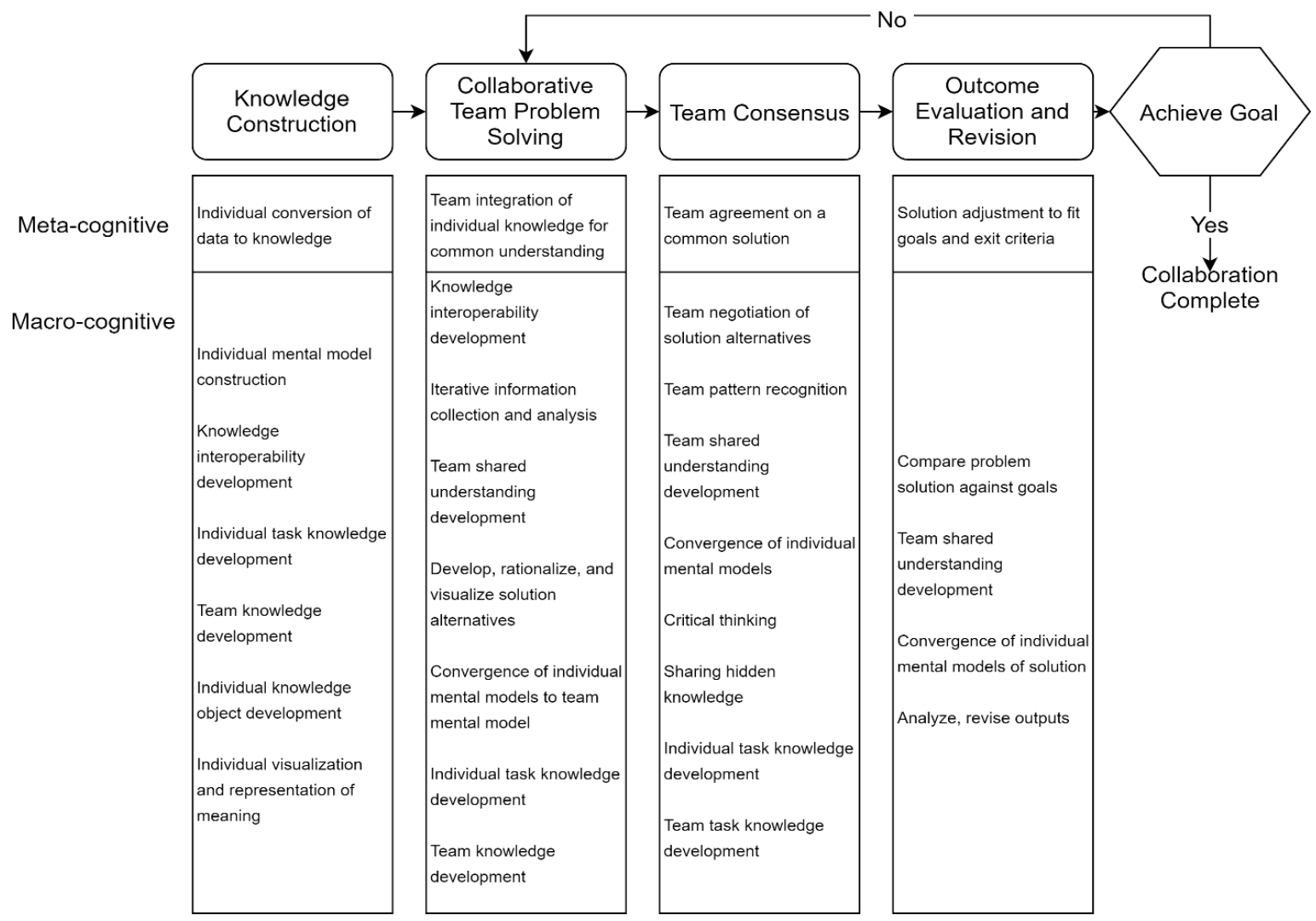

Figure 2. Group and individual cognitive processes during collaboration (Warner, Letsky \& Cowen, 2005)

This model can be mapped onto the cognitive model of the inquiry process (Zhang et al, 2010, see Figure 3), demonstrating that collaborative problem solving still follows the same process as individual problem solving. The primary difference is that in the beginning of the inquiry process, identification of the problem and searching possible solutions are distributed among group members who then combine their knowledge to collaboratively select and evaluate a solution. 


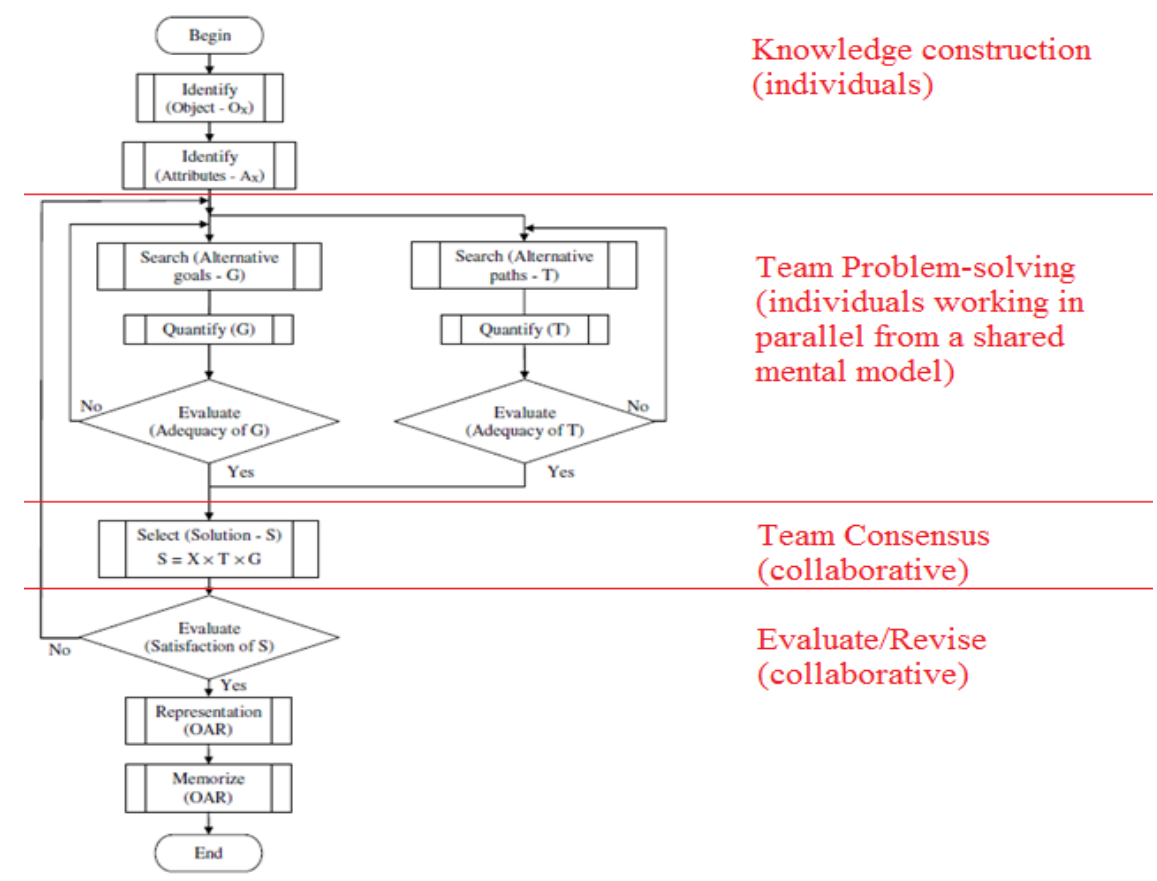

Figure 3. Mapping the team collaboration model onto the inquiry process model

Sutton (2013) states that when people collaborate, their alignment is simultaneously perceptual, cognitive, motivational, and affective. They try to see and understand each other's perspectives while encouraging each other and trying to be accepted as part of the group. As a result, collaboration may help people solve problems that are more complex than they could solve independently. The benefits of collaboration can be enhanced when the participants share experiences, such as culture or technology, or can be restricted when there is an uneven distribution of knowledge. Similarly, the epistemology of the individuals with respect to the context influences the effectiveness of the collaboration for problem solving (Hofer, 2001). Individuals have different perspectives on knowing that depend on the situation. For example, a person may view mathematics as absolute and games as complex. When an individual believes knowledge is absolute, collaboration puts that individual in a position of determining the "right" answer rather than seeing the different perspectives as equal possibilities, which is what more sophisticated epistemological development allows. Therefore, when considering how collaboration influences problem solving, the individual epistemologies within that context should also be considered.

Because experience helps the problem solving process, remembering key information from a problem solving experience would strengthen the skills one would need in a future endeavor. But does collaboration help individuals recall information? Suparna Rajaram (2011) suggests that collaboration both helps and harms recall. She reviewed several of her own studies as well as those conducted by others concerning memory effects when collaborating and found that working with others re-exposes the individual to knowledge he/she once had while correcting misconceptions he/she may have held about that knowledge. As a result, the knowledge is easier for the individual to recall and likely to be more accurate. However, working with others can also produce collaborative inhibition. Sharing information with others present increases the chances that another will interrupt one's thoughts, disrupting the retrieval of information, or may cause an individual to refrain from sharing because of a perceived taboo on the subject or a feeling of not being knowledgeable enough to speak in the group. Not only does this inhibition reduce the recall abilities of the group members as Rajaram found, it can cause an uneven distribution of 
knowledge which Sutton (2013) claimed could restrict the problem solving capabilities of the group.

Warner, Letsky and Cowen (2005) found that a key mechanism of the collaborative problem solving model was communication. Sharing information and negotiating perspectives enhance the problem solving capabilities of the group. To test this mechanism, they collected data from two separate types of collaborations, teams that met in person and teams that collaborated asynchronously online. The teams that met in person had significantly more communication than the asynchronous teams did. The nature of the communication was also different between the two types of groups. The in-person groups spent more time in discussions during the knowledge construction stage while the asynchronous teams spent more time in the problem solving stage. Both types of groups found viable and satisfactory solutions to their problems. This suggests that the creation of a shared mental model is critical to solving a problem with others and requires the most communication; the in-person groups likely developed a shared model as they communicated their initial knowledge and understandings, while the asynchronous groups likely developed that shared model when they needed to explore possible solution paths.

In contrast, Blooma, Kurian, Chua, Goh and Lien (2013) observed interactions within an online forum designed for students to ask and receive help from each other. They hypothesized that these forums would enable micro-collaborations for problem solving to occur and thus analyzed the conversations for evidence of higher-ordered thinking as described in Bloom's taxonomy. Instead, they found that students mostly reached out to one another only to share factual or procedural knowledge. They also saw that most posts were students seeking to understand or explaining a concept rather than applying or synthesizing concepts. Even though these students were in the same class, and thus would be trying to solve similar problems, they did not establish a model of collaborative problem solving.

These studies suggest that there exists a particular mechanism that is especially useful for problem solving with others and that appears during conversations. According to two other studies, this mechanism is the process of explaining reasoning to another person. Robert Siegler (1995) studied forty-five preschoolers who were learning number conservation with an adult. Each child was given a series of problems that showed two parallel rows of objects with an equal number of objects in each row and, as one row was lengthened or shortened, were asked if the rows contained the same number of objects. One-third of the children received only brief feedback indicating if the answer was correct or not, one-third was asked to explain his/her reasoning before receiving feedback, and the remaining third received feedback then were asked to explain the adult's reasoning for the feedback. This experiment was conducted over four sessions with pre- and post-tests measuring growth. The group that was asked to explain the adult's reasoning answered correctly during the sessions $62 \%$ of the time overall, compared to $48 \%$ and $49 \%$ for the other groups, and their explanations increased in sophistication as the experiment progressed. Additionally, the post-test for this group showed about twice the growth of the other two groups, which showed approximately equal growth.

van Blankenstein, Dolmans, van der Vleuten and Schmidt (2011) worked with college students but found similar results. Undergraduates participated in a simulated group discussion after receiving information about an unfamiliar topic. One group was asked to only listen to the actors discussing the material, one group listened to actors discussing the material and asking each other, but not the participant, to elaborate his/her reasoning, and the third group conversed with the actors where the actors asked him/her to explain his/her reasoning or to elaborate. Posttests were given immediately after the session and one month following. The participants who were asked to explain and elaborate were able to recall more information than the other two groups on both measures. The group that listened to others reason performed better than the listen-only group on the first post-test but both groups were at the same level one month later. 
Providing explanations during collaboration appears to have the most impact for improving problem solving skills on lower-skilled participants when they work with higher skilled peers. Fawcett and Garton (2005) studied 100 children ages 6-7 performing sorting activities. After pretesting to determine individuals' sorting skills, children were partnered with a samegender child in one of the following conditions: high pretest score with high, low with low, low with high, and no partner (control). In half of the partnered groups, one child was asked to explain what to do while the other did the sorting activity; in the other half, children were asked not to talk to each other and completed the sorting activities individually. Post-testing showed that the only one condition resulted in an average increase of more than one problem correct (out of nine problems), and that was when low-scoring children explained what to do to high-scoring partners. These children had an average gain of 2.1 problems correct.

Likewise, Taylor and McDonald (2007) worked with undergraduate students who had a history of struggling in mathematical problem solving. At first, these students worked in small groups with the assistance of a tutor on a series of non-routine problems in math. Students were given guidance on how to work together and on generic problem solving strategies but were not helped with the problems. The researchers found that students were not improving in their problem solving or math communication skills enough to handle the more complex problems they would be working on later. The researchers then modified these collaborative workshops so that the students were required to write a group report on the problem and their solution. The groups were provided with a heuristic for their report and were encouraged to complete each section of the heuristic as its corresponding problem solving step was completed, rather than do the entire report at the end. The tutors shifted their roles so that they were providing feedback on the writing rather than the problem solving. This shift changed the explanation-giving from like-skilled peer communication to lower-skill explaining to higher-skill as the tutor was asking for clarification from what the students wrote. As a result, the students gained both problem solving and communication skills and were able to solve the more difficult problems at the end of the study easier than they were able to solve the simpler problems at the beginning.

These studies show that providing explanations and being prompted for further detail or to consider another's viewpoint increases the individual's abilities to reason and to recall information, key skills when problem solving. Additionally, the skill levels of the person providing and receiving the explanation affect the level of impact that these explanation-giving activities will have on increasing problem solving skills. When the person providing the explanation is of lower skill compared to the person receiving the information, such as a child to an adult or a student to a tutor, then the lower-skill person increases his/her problem solving abilities more than if the reverse were true or if their skill levels were closely aligned.

\section{Collaboration and problem solving in formal environments}

Although the research shows that collaboration has benefits while problem solving, these benefits cannot be realized unless the people who should be collaborating see value in that process. Formal environments such as workplaces and classrooms may provide opportunities for, or even requirements for, collaboration, but the individual's perspectives and social skills may determine what benefits are actualized during such a collaboration.

The first aspect that might affect problem solving collaborations could be how the individual views risk. This view could affect what level of challenge the individual is willing to accept, which could then define his/her role in the collaboration. Meyer, Turner and Spencer (1997) studied the challenge-seeking behaviors of fourteen late-elementary students. Specifically, they measured each child's affect, achievement goals, academic risk-taking, self-efficacy, and volition then compared that to the child's behavior when working on a math project. This study found that the children who liked academic challenge and risk had a higher level of metacognition 
than those who avoided challenge did, allowing them to use the difficulties they encountered in their projects as learning opportunities. They also defined success in terms of having a successful product rather than extrinsic factors such as grades or the positive opinions of others. The students who were challenge-avoiders, however, sought ways to simplify the project in order to avoid the difficulties encountered even when they knew they would receive a lower grade. It therefore would be easy to assume that one would want all challenge-seekers in a collaboration, but other research has found that individual characteristics may not affect the group significantly after all.

Lee, Huh and Reigeluth (2015) observed two high-school classes that engaged in project-based learning. Project-based learning was a regular occurrence in these classrooms, so the students were accustomed to collaboration while problem solving and inter-group conflict was a normal part of these collaborations. The researchers hypothesized that individual and grouplevel social skills could each impact the level of conflict or collaboration that the group experienced. What they found, however, is that the group's social skills had a higher level of impact than the individual had. An individual with poor social skills did not have a significant effect on the inter-group conflict if the group as a whole understood negotiation and other social skills required for collaboration. Therefore, as Figure 4 shows, an individual's characteristics may not significantly affect the group as long as the group has strong collaboration skills collectively.
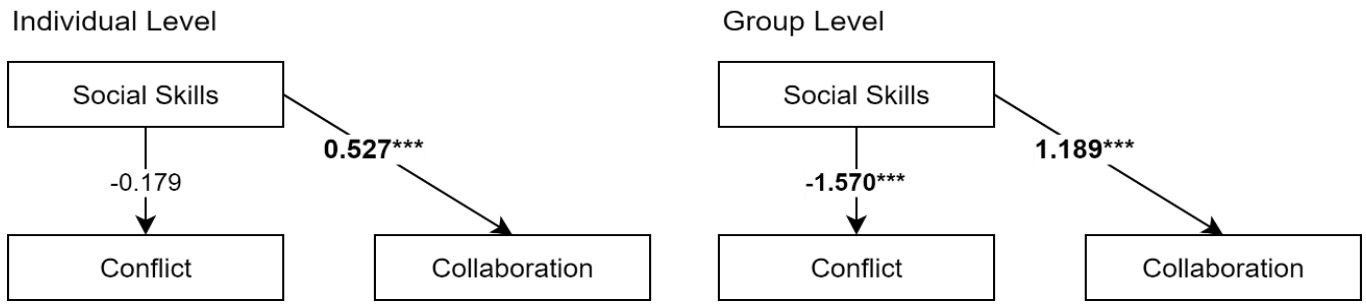

Figure 4. Impact of social skills on conflict and collaboration at both the individual and group level ${ }^{* * *} \mathrm{p}<0.001$ (Lee, Huh \& Reigeluth, 2015)

In engineering, Kim and King (2004) observed intra-group conflict that happens when the product that the groups collaboratively developed shows a problem. Three groups of engineers worked on different aspects of a specialized chip, with each group being responsible for one aspect of the chip's design. When problems arose, each group suggested a possible cause for the problem in such a way that the responsibility to fix the problem would mostly fall on another group rather than their own. These suggestions were not offered as a means of avoiding challenge but because each group failed to see how the problem could be with their part of the design. To resolve such conflicts, the three teams adopted social norms that included sharing of expertise and listening to other's reasoning. The solution still placed the responsibility on one or two groups, but the solution was collaboratively agreed upon in each instance and the responsible group(s) were not the same for each problem. These findings reflect the model shown in Figure 5 in that the social skills between the groups both created conflict, when they saw issues as being another's responsibility, and enabled collaboration, when they shared expertise to arrive at a possible solution.

Another study demonstrates that employees value collaboration because they see it as necessary for successful problem solving. Itabashi-Campbell, Gluesing and Perelli (2012) interviewed thirty-one engineers in a variety of industries about the proximal processes involved in both their successes and failures. The engineers had five attributes common to their successes in problem solving: The external leadership provided clear goals and remained involved in the process, the engineers had the autonomy to change designs or seek help without political consequences, they had access to the people and materials they needed to solve the problem, all stakeholders maintained a sense of controlled urgency where they neither panicked nor relaxed too much, and there were systems in place for sharing information and processes. Their failure 
stories involved inertia, confusion, and disinterest by at least one stakeholder and the situation become one of placing blame rather than solving the problem. When the researchers evaluated the success and failure stories closer, they found that all of the successes also had five processes in common while the failures were each missing at least one of the processes. These processes were (1) communicating the problem to all involved parties, (2) investigating the problem, (3) determining the root cause of the problem and identifying a solution, (4) implementing the solution, and (5) distributing the learning to all stakeholders. Most notably was that all of the engineers verbalized the positive value they placed on collaboration through these proximal processes, with one engineer even reporting how he "forced" a collaboration to occur in order to obtain the different perspectives he needed to solve a problem with the product.

An additional proximal process that can have positive impact on one's career in academia at least is social connectedness. A study (Ozel, 2012) examined the publications of Turkish management researchers from 1922 through 2008 for who the researchers collaborated with, what topics they wrote about, and, where possible, how many professional groups each researcher belonged to. Researchers who published internationally tended to collaborate with other researchers in the same field, demonstrating a deep social connectedness within that field of study. Researchers who published nationally, however, showed greater diversity in who they collaborated with, demonstrating a broader, but perhaps shallower, social connectedness than the internationally-published researchers. Similarly, those with deeper social connectedness within one field of study and/or with involvement in several professional groups tended to publish mostly about mainstream issues. The study also suggested that these highly-connected researchers could be determining what those mainstream issues are when they publish because they also appear to be publishing at the beginning of the issue as well as later.

Collaboration in formal settings has many benefits, from career advancement to solving product issues. They can only be successful, however, when the group has agreed-upon social norms and structures for collaborating. When these structures are in place, the effect of an individual's skills are minimized so that negative skills will not prevent the group from finding a solution. Other proximal processes in the workplace can provide additional supports for problem solving and career advancement. These include being able to communicate with people outside of the group and networking with others in the field but outside of the geographical area.

\section{Problem solving and collaboration in game spaces}

Game spaces provide unique opportunities for proximal processes and problem solving because they have low stakes for failure, allowing greater risk-taking behavior, and challenges that elicit both competition and collaboration (Gee, 2007). These opportunities can exist in both video games and in-person games such as board games. The characteristics of these collaborations are similar to those found in formal environments, but the characteristics of who is participating in the collaboration has less to do with perspectives towards challenge and more to do with self-efficacy within the environment. Additionally, the genre of the game can be seen as a proximal process in that different genres have different effects on the player's personal identity and stress level.

The primary communication found within a game space is the sharing of information or ideas, but this tends to precede critical thinking discussions. Marc Cicchino (2015) developed a social studies board game for eighth graders that emulated the French and Indian War in colonial America. Students formed teams that represented each of the nations involved in the conflict, with each team provided with different start and end conditions for the game. The game encouraged alliances between the "nations," so the children engaged in both inter- and intragroup discussions. Cicchino found that most of what the students said were to share or clarify an idea, but most of these statements then lead to a discussion among the children that involved 
critically thinking about the problem they were trying to solve within the game. Negotiation and co-constructing knowledge were the next most common statements, demonstrating that even in a game environment the children were following the model of team collaboration (Warner, Letsky \& Cowen, 2005) described earlier.

Another study (Shih, Shih, Shih, Su \& Chuang, 2010) demonstrated that within a game having a low-skill player explaining to another player has more benefits for learning problem solving skills than having a high-skill player explain. They had two eleven-year old girls play a video game for problem solving individually for an hour then partnered each with a boy of the same age. During the individual sessions, one girl demonstrated lower problem solving skills than the other; she randomly tried approaches to the puzzles rather than systematically finding solutions and she did not apply learning from previous puzzles to new scenarios like the other girl did. When partnered, however, she was able to complete more puzzles than the more systematic player and her partner were able to complete. The conversations between partners helps demonstrate why. When both girls were going through the areas of the games they experienced before, they controlled the computer and the boys each observed. However, the girl who had difficulty on her own explained to her partner what was happening in the game while the other girl did not communicate with her partner at that time. When each pair encountered puzzles that the girls had not previously seen, the first girl worked with her partner to collaboratively find solutions. By the end of the game, she was demonstrating a more systematic approach to the puzzles, which she learned from her partner. The other girl, however, maintained control of the game even with the new puzzles. When her partner had an idea, he tried to take control of the computer rather than share his idea with her, resulting in arguments rather than collaboration. This study might demonstrate one reason why lower-skilled people explaining to higher-skilled people has greater benefits for learning problem solving than other configurations; higher-skilled people may be reluctant to share their learning with others.

Social ties and perceived expertise also influence collaboration in game spaces. Bluemink, Hamalainen, Manninen and Jarvela (2010) observed the interactions between college students playing a puzzle-based role-playing video game. Some of the students had prior social ties with others in their group or had prior experience playing video games in this genre while others did not. Similar to the history board game study, this study found that most of the conversations concerned information and idea sharing and that these led to critical thinking discussions. However, the discourse in each group was dominated by the person(s) who had prior social ties or gaming experience while the person who knew nobody in the group and who did not play games talked the least. Additionally, the nature of the conversations was different depending on who was in the group. Groups who has experienced gamers in them also had more conversation statements that involved giving instructions or orders than the other groups had, while the other groups had more information-sharing statements and conversations around ideas. This study also suggests a reason why having a high-skilled person explaining is less beneficial; that person might demonstrate their knowledge through instructions rather than explanations.

Hou (2013) also demonstrated that self-efficacy within a game environment effects the number of interactions that the player will have. Fourth graders in Taiwan played a massivelymultiplayer game designed to strengthen English language acquisition. All participants, regardless of gender or ability, engaged in approximately the same number of learning activities, but those with higher English skills also participated in more interactions with other players and with nonplayer characters than those with lower skills did. These interactions often led to other interactions within the game, resulting in the students with higher skill levels receiving more conversational practice than the other students received.

A significant benefit that game spaces have over other environments for learning and problem solving is the competition between players inherit to most games. Cagiltay, Ozcelik and Ozcelik (2015) modeled the effect that a learning game for computer science had on college 
students' understanding of databases. As Figure 5 demonstrates, they found that competition between players had a positive effect on motivation, which increased player's accuracy and resulted in significant gains on the post-test. Competition and motivation did not have a significant effect on the students' response times. This suggests that the proximal processes could be competitive rather than collaborative in nature and still be beneficial for problem solving within a game.

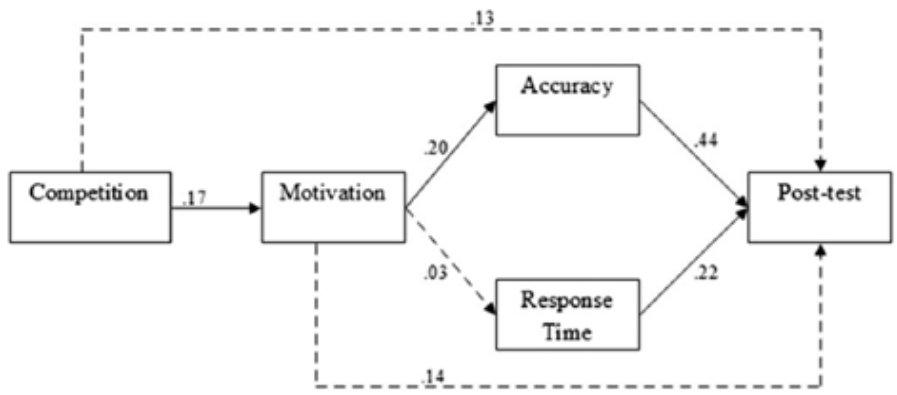

Figure 5. Standardized path coefficients showing the effect of competition

(Cagiltay, Ozcelik \& Ozcelik, 2015).

Playing video games recreationally may also be related to understanding science. Fraser, Shane-Simpson and Asbell-Clarke (2014) surveyed 1502 teens on their gaming habits, science self-efficacy, and science scores. $94 \%$ of those surveyed had played a video game at least once in the previous week. Students who preferred first-person shooter games, race games, or problem solving games had stronger self-efficacy and scores in science than those who played other types of games. Although most of these teens did not play with others, online or in person, they did discuss games regularly with peers and with online affinity groups. Additionally, all three of the preferred game genres involve interactions with non-player characters in either a competitive or collaborative setting.

Collaborating in game spaces is similar to collaborating in formal environments in that the team collaborations follow the same problem solving processes in both areas and that they especially benefit lower-skilled participants when they explain ideas to higher-skilled participants. Game spaces have an additional proximal process, however, which is competition. Competition increases motivation, which in turn increases one's problem solving skills and learning. Using game spaces for problem solving can be problematic, however, when one participant has lower self-efficacy in that environment. The group will still be able to solve the problem, but the selfefficacy of each participant will influence how much he/she participates.

\section{Discussion}

Problem solving follows a cycle of inquiry where the individual iterates between finding possible paths and exploring their likely effectiveness before selecting one as a possible solution. This cycle can be greatly enhanced through collaboration because the number of paths that can be explored in depth are greater when more people work on the same problem. This enhancement emulates the problem solving process of expert chess players when they are familiar with the board state in that paths can be explored in greater depth without requiring that each individual be an expert in the problem scenario.

The key benefit collaboration has for problem solving is in the providing of explanations, as long as the person communicating has less skill than the person listening. This is likely due to the listener asking for clarification or deeper reasoning in order to understand the speaker correctly, as was shown in the simulated conversations studied by van Blankenstein, Dolmans, van der Vleuten and Schmidt (2011). When a higher skilled person has to explain to a 
peer or a lower skilled person, they tend to give instructions rather than reasons, at least in game environments. However, a lower skilled person may feel reluctant to participate in conversation, thus reducing their opportunities to learn. Having structures in place for collaborating would help alleviate both higher-skilled dominance and lower-skilled hesitance. Collaboration structures also support successful problem solving by minimizing the effect that any individual has on the group.

Although the benefits of proximal processes for problem solving are well explained in the literature included in this paper, the limited number of studied is of some concern. The focus on collaboration shown in these studies limits the discussion to only those proximal processes that occur within a defined group. Lacking in the literature is the understanding of how proximal processes can evolve or support problem solving outside of a group collaboration. Additionally, it might be worth understanding who is likely to seek others when problem solving, under what conditions, and who those "others" would be. For example, if lower-skilled people benefit most by explaining their reasoning to others, are they also the people most likely to seek others to work with? Or will low self-efficacy prevent them from discussing the problem with others? Further understanding of the proximal processes for problem solving could benefit student-retention research in high problem solving majors such as engineering, corporate responses to product failures, and the development of problem solving skills in children.

\section{Acknowledgements}

This research did not receive any specific grant from funding agencies in the public commercial, or not-for-profit sectors.

The author declares no competing interests.

\section{References}

Bilalic, M., McLead, P., \& Gobet, F. (2009). Specialization effect and its influence on memory and problem solving in expert chess players. Cognitive Science, 33, 1117-1143.

Blooma, M., Kurian, J., Chua, A., Goh, D., \& Lien, N. (2013). Social question answering: Analyzing knowledge, cognitive processes, and social dimensions of micro-collaborations. Computers and Education, 69, 109-120.

Bluemink, J., Hamalainen, R., Manninen, T., \& Jarvela, S. (2010). Group-level analysis on multiplayer game collaboration: How do the individuals shape the group interaction? Interactive Learning Environments, 18(4), 365-383.

Cagiltay, N., Ozcelik, E., \& Ozcelik, N. (2015). The effect of competition on learning in games. Computers and Education, 87, 35-41.

Cicchino, M. (2015). Using game-based learning to foster critical thinking in student discourse. Interdisciplinary Journal of Problem Based Learning, 9(2).

Fawcett, L. \& Garton, A. (2005). The effect of peer collaboration on children's problem-solving ability. British Journal of Educational Psychology, 75, 157-169.

Fraser, J., Shane-Simpson, C., \& Asbell-Clarke, J. (2014). Youth science identity, science learning, and gaming experiences. Computers in Human Behavior, 41, 523-532.

Gee, J. P. (2007). What video games have to teach us about learning and literacy. NY: Palgrave MacMillan.

Gee, J. P. (2013). The anti-education era: Creating smarter students through digital learning. NY: Palgrave MacMillan. 
Goldman, A. (1983). Epistemology and the theory of problem solving. Synthese, 55(1), 21-48.

Hofer, B. (2001). Personal epistemology research: Implications for learning and teaching. Journal of Educational Psychology Review, 13(4).

Hou, H. (2013). Analyzing the behavioral differences between students of different genders, prior knowledge and learning performance with an educational MMORPG: A longitudinal case study in an elementary school. British Journal of Educational Technology, 44(3).

Itabashi-Campbell, R., Gluesing, J., \& Perelli, S. (2012). Mindfulness and product failure management: An engineering epistemology. International Journal of Quality \& Reliability Management, 29(6), $642-665$.

Kim, J., \& King, J. (2004). Managing knowledge work: Specialization and collaboration of engineering problem-solving. Journal of Knowledge Management, 8(2), 53-63.

Lee, D., Huh, Y., \& Reigeluth, C. (2015). Collaboration, intragroup conflict, and social skills in project based learning. Instructional Science, 43, 561-590.

Meyer, D., Turner, J., \& Spencer, C. (1997). Challenge in a mathematics classroom: Students' motivations and strategies in project-based learning. The Elementary School Journal, 97(5).

National Governors Association Center for Best Practices, \& Council of Chief State School Officers (2010). Common Core State Standards. Washington D.C.: National Governors Association Center for Best Practices, Council of Chief State School Officers.

Ozel, B. (2012). Individual cognitive structures and collaboration patterns in academia. Scientometrics, 91, 539-555.

Partnership for $21^{\text {st }}$ Century Learning (2015). P21 Framework Definitions. Retrieved from http://www.p21.org/about-us/p21-framework.

Rajaram, S. (2011). Collaboration both hurts and helps memory: A cognitive perspective. Current Directions in Psychological Science, 2O(2).

Shih, J., Shih, B., Shih, C., Su, H., \& Chuang, C. (2010). The influence of collaboration styles to children's cognitive performance in digital problem-solving game "William Adventure": A comparative case study. Computers and Education, 55, 982-993.

Siegler, R. (1995). How does change occur: A microgenetic study of number conservation. Cognitive Psychology, 28, 225-273.

Sutton, J. (2013). Skill and collaboration in the evolution of human cognition. Biological Theory, 8, 28-36.

Taylor, J. A., \& McDonald, C. (2007). Writing in groups as a tool for non-routine problem solving in first year university mathematics. International Journal of Mathematical Education in Science and Technology, 38(5), 639-655. https://doi.org/10.1080/00207390701359396

van Blankenstein, F., Dolmans, D., van der Vleuten, C., \& Schmidt, H. (2011). Which cognitive processes support learning during small group discussion? The role of providing explanations and listening to others. Instructional Science, 39(2), 189-204.

Warner, N., Letsky, M., \& Cowen, M. (2005). Cognitive model of team collaboration: Macro-cognitive focus. Proceedings of the Human Factors and Ergonomics Society $49^{\text {th }}$ Annual Meeting.

Zhong, N., Wang, Y., \& Chiew, V. (2010). On the cognitive process of human problem solving. Cognitive Systems Research, 11, 81-92. 
L. A. Jacques - Proximal Processes While Problem Solving in...

C O A $\mathrm{s}$ 